\title{
The study of social inequalities in health in Spain: where are we?
}

Compared with central, northern, and eastern European countries, Spain presents intermediate levels of wealth, measured in terms of the Gross Domestic Product per capita. Thus while central and northern European countries have $38 \%$ of the population and $81 \%$ of the wealth, the countries of southern Europe have $17 \%$ of the population and $10.7 \%$ of the wealth. Eastern European countries are even worse off with $45 \%$ of the population and only $8.2 \%$ of the wealth It should be noted that in recent years Spain is one of the countries with the highest level of unemployment in Europe (18.6\% in 1998, third trimester). ${ }^{12}$

The study of social inequalities in health in Spain is still recent, with an increase in the number of studies carried out in the past decade. Most of the studies are descriptive, and there are to date very few studies of trends, and none that attempt to investigate reasons for social inequalities in health. Five years ago, the socialist government named a Scientific Commission to study social inequalities in health in Spain. The commission published a report in $1996,{ }^{3}$ but was not widely disseminated by the new conservative government, and its recommendations have scarcely been implemented. The forums where this report should have some impact are mainly policy makers, public administration, and public health workers.

The pattern of social inequalities in health in Spain, as in other countries of southern Europe, presents certain differential characteristics compared with central and northern European countries. Thus for example in Spain AIDS, which presents the highest incidence rates of the European Union and which is the primary cause of death in the young population, has higher incidence among the more disadvantaged socioeconomic levels ${ }^{4}$ or ischaemic heart disease mortality that hardly differs between manual and non-manual classes in men. ${ }^{5}$ Another example is the consumption of tobacco and alcohol by social class, among men there is a slight gradient, with the more disadvantaged classes consuming more, whereas in women consumption is more prevalent among those of higher socioeconomic level. ${ }^{367}$

Most of the studies on social inequalities in health carried out in Spain have been based on mortality statistics. Individual based studies are few, because of the absence, or poor quality, of information on socioeconomic characteristics in death certificates, together with a more restrictive legislation regarding the use of individual data than in northern and central European countries. ${ }^{8}$ The only individual based studies that it has been possible to carry out have been done in the eight provinces where occupation was more consistently available in the death certificate, and in a few cities where it was possible to link local census socioeconomic information with the death register. These studies have shown higher mortality among the more disadvantaged social classes for most causes of death, differences that have increased over the period from 1980 to $1990^{\circ}$; they have also shown the importance of these social inequalities in some causes of death, specially in AIDS and drug overdose among the young population of some cities. ${ }^{4}{ }^{10}$ There is a greater abundance of ecological studies using all 52 provinces, or the 17 Autonomous Communities as the unit of analysis, ${ }^{11}{ }^{12}$ or of studies carried out in small areas of some city or region ${ }^{13}{ }^{14}$ with all studies finding an association between mortality and socioeconomic level.

The analysis of mortality in small areas of Spain offers the opportunity to analyse inequalities in more detail, this being the objective of the article by Benach and Yasui that appears in this issue of the journal. ${ }^{15}$ In this study the geographical patterns of mortality and the relation between deprivation and mortality are analysed in 2200 small areas. Two indices of deprivation are obtained: one related to overcrowding, illiteracy, and low social class, and the other related mainly with unemployment. The percentage of people with low social class ranges from $59 \%$ in Andalucia to $35.4 \%$ in Balearic Islands (excluding Ceuta and Melilla). A geographical pattern of increasing mortality and deprivation from north east to south west is found. Excess mortality in deprived areas is estimated at 35000 deaths. This is the first ecological study in Spain that enables the social inequalities in mortality to be described at the level of small geographical areas and it allows us to understand the pattern of inequalities better than province based studies. This study is useful for delimiting small areas of the country with greater need of intervention.

The study of social inequalities in perceived health status, health related behaviours and the utilisation of health services, has usually been carried out based on health surveys. It should be noted that the various different surveys carried out in Spain do not provide information on social variables that are mutually comparable, making difficult the study of trends. Other sources of information (birth registers, specific disease registers, etc) do not carry social variables, or they are very incomplete. There is no routine collection of social variables in information provided through health services (discharge registers, primary care morbidity registers, etc) ${ }^{8}$

The more disadvantaged social classes present poorer perceived health status and more chronic illness. There is at present a change in tobacco consumption as a function of social class, with the prevalence of smoking increasing among lower class men, while women in the higher classes are tending to smoke more, although the differences have become less marked with time. ${ }^{367}$ With respect to the utilisation of health services, we can state that the universalisation of the National Health System in Spain facilitates access to services for all social classes, but there are inequalities in other aspects related to health care, such as, for example, waiting list times, or the access to preventive health services (for example, dentistry services, prevention of breast cancer, etc). ${ }^{316} 17$

Despite the progresses achieved, and now that we are beginning to understand the current situation in the country, it is necessary to continue advancing. Availability and quality of current sources of information must improve, both in reference to social information and to the possibility of linking registers. Research into social inequalities in health should be a priority, with increases in both institutional funding and in dedication of professionals. It is necessary to go more deeply into studies both of a descriptive nature and of trends, particularly in certain areas of Spain for which there is practically no scientific evidence, but also studies should be initiated to deepen the knowledge of the causes of social inequalities in health, and 
to study the effectiveness of health and social policy directed at their reduction.

Municipal Institute of Public Health, Pl Lesseps 1, 08023 Barcelona, Spain

Correspondence to: Dr C Borrell.

1 Statistics Division of the United Secretariat and International Labour Office. Indicators on income and economic activity. United Nations, 1998. http://www.un.org/Depts/unsd/social/inc-eco.htm

2 Encuesta de población activa (tercer trimestre). Madrid: Instituto Nacional de Estadística, 1998.

3 Navarro V, Benach J y la Comisión científica de estudios de las desigualdades sociales en salud en España. Desigualdades sociales en salud en España. Madrid: Ministerio de Sanidad y Consumo y The School of Hygiene and Public Health, The Johns Hopkins University, 1996.

4 Borrell C, Regidor E, Arias LA, et al. Inequalities in mortality according to educational level in two large Southern European cities. Int $\mathcal{f}$ Epidemiol 1999;28:58-63.

5 Kunst AE, Groenhof F, Mackenbach JP and the EU Working Group on Socioeconomic Inequalities in Health. Occupational class and cause specific mortality in middle aged men in 11 European countries: comparison of population based studies. BMf 1998;16:1636-42.

6 Regidor E, Gutiérrez-Fisac JL, Rodríguez C. Diferencias y desigualdades en salud en España. Madrid: Díaz de Santos, 1994.
7 Socio-economic differences in smoking in 12 European Countries. In: Cavelaars A. Cross-national comparisons of socio-economic differences in health indicators. [Thesis]. Rotterdam: Erasmus University, 1998.

8 Grupo de trabajo de la Sociedad Española de Epidemiología. La medición de la clase social en ciencias de la salud. Barcelona: SG Editores, 1995.

9 Regidor E, Gutiérrez-Fisac JL, Rodríguez C. Increased socioeconomic differences in mortality in eight spanish provinces. Soc Sci Med 1995;41:801-7.

10 Fernández E, Borrell C. Cancer mortality by educational level in the city of Barcelona. Br f Cancer 1999;79:680-3.

11 Lardelli P, Blanco JI, Delgado- Rodríguez $\mathrm{M}$, et al. Influence of socioeconomic factors and health care development on infant and perinatal mortality in Spain. Soc Sci Med 1993;378:413-17.

12 Vàzquez-Vizcoso $\mathrm{F}$, Castilla J, Pollán $\mathrm{M}$, et al. Assessment of trends in geographical inequalities in infant mortality. Soc Sci Med 1993;378:413-17.

13 Arias A, Rebagliato M, Palumbo MA, et al. Desigualdades en salud en Barcelona y Valencia. Med Clin (Barc) 1991;100:281-7.

14 Borrell C, Pasarín MI, Plasència A, et al. Widening inequalities in mortality: the case of a southern european city (Barcelona). $\mathcal{F}$ Epidemiol Community Health 1998;51:659-67.

15 Benach J, Yasui Y. Geographical patterns of excess mortality in Spain explained by two indices of deprivation. $\mathcal{F}$ Epidemiol Community Health 1999;53:423-31.

16 Regidor E, de Mateo S, Gutiérrez-Fisac JL, et al. Diferencias socioeconómicas en los servicios sanitarios en España. Med Clin (Barc) 1996:107:28588 .

17 Rohlfs I, Borrell C, Pasarín MI, et al. Social inequalities and realisation of opportunistic screening mammographies in Barcelona (Spain). F Epidemiol Community Health 1998;52:205-6. 